\title{
US States' Childhood Obesity Surveillance Practices and Recommendations for Improving Them, 2014-2015
}

\author{
Kelly J. Blondin, MS; Catherine M. Giles, MPH; Angie L. Cradock, ScD; \\ Steven L. Gortmaker, PhD; Michael W. Long, SD
}

\begin{abstract}
Suggested citation for this article: Blondin KJ, Giles CM, Cradock AL, Gortmaker SL, Long MW. US States' Childhood Obesity Surveillance Practices and Recommendations for Improving Them, 2014-2015. Prev Chronic Dis 2016;13:160060. DOI: http://dx.doi.org/10.5888/pcd13.160060.
\end{abstract}

\section{PEER REVIEW}

\section{Abstract}

\section{Introduction}

Routine collection, analysis, and reporting of data on child height, weight, and body mass index (BMI), particularly at the state and local levels, are needed to monitor the childhood obesity epidemic, plan intervention strategies, and evaluate the impact of interventions. Child BMI surveillance systems operated by the US government do not provide state or local data on children across a range of ages. The objective of this study was to describe the extent to which state governments conduct child BMI surveillance.

\section{Methods}

From August through December 2014, we conducted a structured telephone survey with state government administrators to learn about state surveillance of child BMI. We also searched websites of state health and education agencies for information about state surveillance.

\section{Results}

State agency administrators in 48 states and Washington, DC, completed telephone interviews ( $96 \%$ response rate). Based on our interviews and Internet research, we determined that 14 states collect child BMI data in a manner consistent with standard definitions of public health surveillance.

\section{Conclusion}

The absence of child BMI surveillance systems in most states limits the ability of public health practitioners and policymakers to develop and evaluate responses to the childhood obesity epidemic. Greater investment in surveillance is needed to identify the most effective and cost-effective childhood obesity interventions.

\section{Introduction}

The dramatic rise in childhood obesity in the United States during recent decades is well-documented (1-3). Height and weight surveillance data were critical in detecting the epidemic and motivating efforts to address it. However, few data are available to assess trends in small geographic areas. No surveillance system used to track childhood obesity nationally collects state-level measured data on height and weight. Biennially the National Health and Nutrition Examination Survey (NHANES) collects measured anthropometric data on a nationally representative, but not state representative, sample of children aged 0 to 19 years (4). For more than 3 decades, the Pediatric Nutrition Surveillance System provided state-level measured data on roughly 8 million children aged 0 to 5 years in low-income households that participated in federal maternal and child health programs, but that survey was discontinued in 2012 (5). The National Survey of Children's Health collects parent-reported data on 95,000 children aged 0 to 17 years (6), and the Youth Risk Behavior Surveillance System collects self-reported data from high school students in most states (7); both of these surveys collect state-representative data, but they rely on reported height and weight, which are less accurate than measured data $(8,9)$.

Previous research on states' measurement of child body mass index (BMI) has focused on identifying state surveillance legislation, describing best practices, and reviewing controversial schoolbased BMI screening programs (10-16). In 2010, one study reported that 19 states had enacted BMI surveillance laws and regula- 
tions, but implementation of these policies lagged (10). Another study found that in 2012, 25 states had legislation requiring school-based BMI screening, but the study did not examine the extent of policy implementation (13).

The aim of this study was to assess US states' child BMI surveillance practices and provide guidance for best practices. To our knowledge, this is the first systematic evaluation of state practices related to childhood obesity surveillance.

\section{Methods}

We surveyed US states to learn about their practices related to childhood obesity surveillance. Consistent with established definitions of public health surveillance (17), we defined a BMI surveillance system as a program that meets 4 criteria: 1) height and weight are measured and reported by a trained professional; 2) data are state representative for the age groups included in the survey or census sample; 3 ) data are collected at least every 2 years with plans to continue; and 4) data are aggregated, analyzed, and reported at the state level.

From August through December 2014, we called the state health agency in all 50 states and Washington, DC, and asked to speak with the person most knowledgeable about child BMI surveillance practices in the state. We invited the identified key informant to participate in a telephone interview via an initial telephone call and up to 3 additional telephone calls or emails. If unable to reach the target individual, we attempted to identify an alternate informant and repeated the outreach and follow-up protocol.

We interviewed the individual identified as the most appropriate contact, using a structured interview guide developed to solicit information about state BMI measurement practices. We asked respondents whether they knew of any efforts in the state to routinely collect and analyze child height and weight data, and we asked a series of questions to determine whether the state's practices met any or all of the criteria we used to define BMI surveillance. The interview included questions about state laws pertaining to physicals children undergo before starting school, state attempts to use electronic health records (EHRs) as a source of surveillance data, and any existing or pending legislation mandating collection of data on child BMI. The interview guide also included questions about funding sources and other resources required to implement a BMI surveillance program. We verified the accuracy and completeness of survey responses through a search of publicly available information on the websites of each state's health and education agencies.
This study was approved by the Office of Human Research Administration at the Harvard Chan School of Public Health.

\section{Results}

Our outreach resulted in telephone survey responses from key informants in 48 of the 50 states and Washington, DC (96\% response rate). For the 2 states from which we did not receive a response, we identified a surveillance system in 1 state (New Mexico) and a school-based BMI measurement program without a data reporting component in the other (New Jersey) from information on the states' health agency websites.

We found that 14 states $(27 \%)$ conduct BMI surveillance consistent with the definition applied in this study (Figure) and that those states collect child height and weight data through several common approaches. Five states collect BMI data through a schoolbased survey, in which data on child health indicators are assessed at school for surveillance purposes only. Three states measure BMI as part of a school-based physical fitness test to assess selected measures that produce a composite score for physical fitness. Five states conduct BMI surveillance by using data collected through a school-based health screen, after which parents or guardians are informed of their child's measurement. A single state collects data on a randomly selected representative sample outside the school setting (Table 1). Our survey found that state government administrators in 5 states were aware of their state conducting pilot evaluations of EHR-based child BMI surveillance.

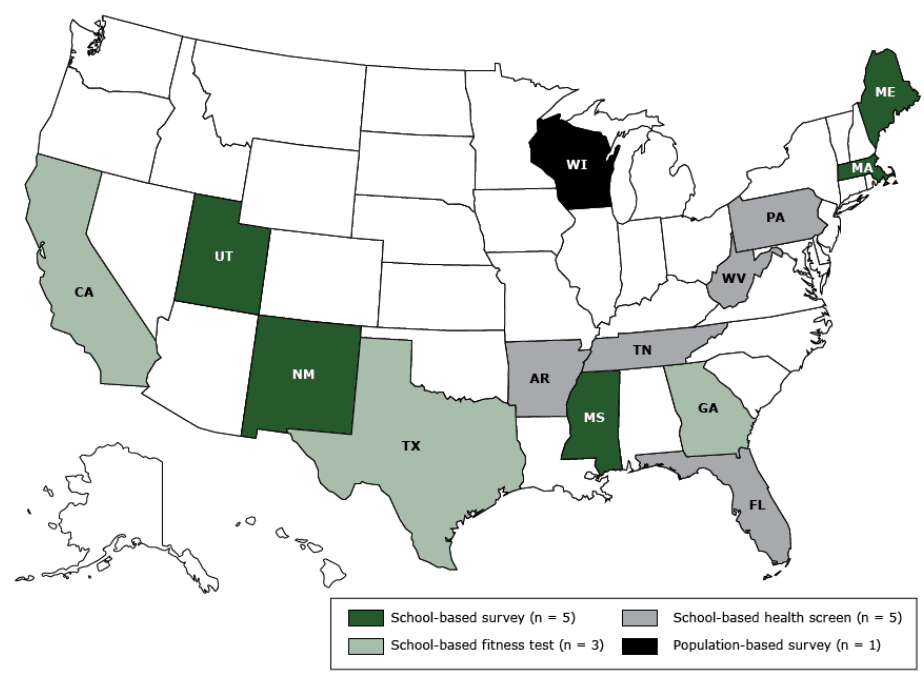

Figure. State childhood obesity surveillance systems in the United States, 2014-2015.

\footnotetext{
The opinions expressed by authors contributing to this journal do not necessarily reflect the opinions of the U.S. Department of Health and Human Services, the Public Health Service, the Centers for Disease Control and Prevention, or the authors' affiliated institutions.
} 
Nine states attempt to take a census of all children in public schools in specific grades, and the other 5 states collect data from a representative sample of children. Coverage across grade levels among states conducting school-based BMI surveillance ranged widely, from a single grade in 2 states to 13 grades in 2 states (mean, 6 grades). Eleven of the states collect data annually and 3 states biennially. Eleven states collect and report locally representative data in addition to state data.

Although only 14 states maintain a surveillance system meeting our study's criteria, most states $(n=35)$ collect child height and weight data. Twenty-one states reported routinely collecting child BMI data but to an extent not fulfilling our standard for surveillance (Table 2). In 7 states, the child BMI data collected are not state representative because, for example, districts collect and report data voluntarily. Six states do not aggregate, analyze, and report the child BMI data they collect, and 8 states collect child BMI data less often than every 2 years (on average, every 5 years). An additional 8 states conducted BMI surveillance at least once, many in the past 2 to 3 years, and some had plans to repeat the surveys.

Of the 14 states, 10 have legislation requiring child BMI surveillance. Pending legislation was not reported by any interviewees. Administrators in 6 states provided estimates of costs related to conducting BMI surveillance, and another 6 cited insufficient funding as an impediment to initiating, maintaining, or fully implementing surveillance efforts.

\section{Discussion}

Our evaluation of US states' childhood obesity surveillance practices found that only 14 operate BMI surveillance programs. States with surveillance programs used the data to detect disparities in the prevalence of overweight and obesity based on socioeconomic status and race/ethnicity. For example, Li and colleagues analyzed more than 1 million BMI records collected on children in grades 1, 4, 7, and 10 between 2009 and 2014 in Massachusetts and found a decline in obesity prevalence overall, but no improvement among children in low-income districts (18). Similarly, Drewnowski and colleagues' analysis of BMI data collected during a census of children in grades 5, 7 and 9 revealed a significant association between California Assembly District poverty status and childhood overweight prevalence (19). Madsen and colleagues also used data from California's statewide school-based BMI measurement program to explore the prevalence of overweight and obesity by race/ethnicity and sex. Their analysis of data collected between 2001 and 2008 on more than 8 million students revealed growing disparities whereby black, Hispanic, and American Indian children were more likely than non-Hispanic white and Asian children to have a high BMI, and black and American Indian girls were the only groups not to show improvement in overweight or obesity (20).

Surveillance data also show risk and protective factors for childhood obesity. For example, Alviola and colleagues analyzed BMI data for Arkansas children in even grades kindergarten through 10 during the 2008-2009 school year and reported an association between a school's proximity to fast food and the prevalence of obesity among its students (21). Likewise, Sage and colleagues used child BMI data collected in Texas public schools to investigate how neighborhood characteristics such as access to fast food, fresh produce, and recreation space relate to neighborhood-level obesity prevalence (22).

Child BMI surveillance data can also be used to assess the impact of childhood obesity interventions on obesity prevalence. Surveillance data collected in Massachusetts, Texas, and California are used to evaluate the effectiveness and cost-effectiveness of multisector, multicomponent demonstration projects in those states (23). Given the value of child BMI data for understanding and mitigating the childhood obesity epidemic, the current shortage of state-level child BMI surveillance data undermines progress.

The practices of the 14 states conducting child BMI surveillance offer guidance on surveillance methods that can meet various budgets and public health planning needs. Ideally, state-level child BMI surveillance systems entail annual data collection on a large sample or census of children of a range of ages. Furthermore, longitudinal data (repeated measures collected on the same children over time) greatly enhance the ability to detect small but meaningful shifts in population-level BMI. Surveillance systems with these qualities provide the best data for identifying disparities in obesity trends, understanding determinants of local variation in obesity prevalence, and evaluating public health interventions locally. Three states (Georgia, Pennsylvania, and Texas) have exemplary surveillance programs; mandated by state laws, they collect BMI data annually on a census sample of children at 10 or more grade levels and can link data on individuals across years at the local level.

However, limited public health resources may hinder optimal state BMI surveillance. By including fewer grade levels, conducting surveys of representative samples, or collecting data every other year, states can conduct meaningful surveillance at a lower cost. Combining BMI measurement with an existing child health surveillance initiative such as the school-based oral health screening program is a cost-efficient surveillance approach (11).

\footnotetext{
The opinions expressed by authors contributing to this journal do not necessarily reflect the opinions of the U.S. Department of Health and Human Services, the Public Health Service, the Centers for Disease Control and Prevention, or the authors' affiliated institutions.
} 
Although school-based measurement is the most common approach for child BMI surveillance, it is not without limitations. Research has identified potential negative effects of collecting height and weight data in schools, including stigma, bullying, body image dissatisfaction, and disordered eating (16). Controversy surrounds the parental notification component central to BMI screening programs (24) and school-based BMI measurement generally (25). Other potential limitations include the cost of data collection, burden on school staff, potentially unreliable data quality, and exclusion of preschool-aged children and children in home or private schools. Some states are exploring alternative settings for collecting BMI surveillance data. Wisconsin is piloting in-home BMI data collection as part of a population-based random sample survey modeled on NHANES. Although this approach reduces the burden on schools and students, unless the sample is large and representative at the school district and/or city level, it will have limited utility for evaluating local trends and the impact of local policy changes and may be expensive.

Interest in using electronic health records (EHR) as a BMI surveillance system is increasing. Since 2009, BMI measurement is a requirement of the Healthcare Effectiveness Data and Information Set, a tool used by more than $90 \%$ of US healthcare plans to measure provider performance $(26,27)$. Moreover, the HITECH Act of 2009 authorized incentive payments to increase physicians' adoption of EHR systems (28). However, EHR uptake by pediatric practices lags uptake by other practice types. As of 2012, only $14 \%$ of pediatric practices had adopted fully functional EHR systems and only $8 \%$ had adopted systems fully supportive of pediatric practice needs, including well-child visit tracking and anthropometric analyses $(27,28)$. However, even universal adoption of EHR systems would not provide complete coverage of child and adolescent populations because of infrequent pediatric visits during later childhood, lack of medical care access among some sociodemographic groups, and frequent change of providers. Nevertheless, given expanded healthcare coverage under the Affordable Care Act and the frequency of pediatric visits, state public health officials will probably continue to explore the potential of EHRbased child BMI surveillance.

This study has several limitations. Although it is a review of statelevel child BMI surveillance practices, it was limited by a lack of information on surveillance program costs and integrity. The survey questions about program costs and resource use did not yield adequate information to produce meaningful cost estimates. Only 6 states operating surveillance programs were able to provide qualitative or quantitative information about program costs during the interview. We learned that funding shortages often undermine surveillance programs and reduce the resources available to operate them; an in-depth analysis of the costs of various surveillance options should be conducted so that policymakers can weigh these costs against the potential benefits. In addition, we were unable to evaluate the quality of height and weight measurement practices in states conducting surveillance, a concern raised by the public health community (29).

Although we found that only 14 states have a child BMI surveillance system according to the definition applied in this study, many states conduct some degree of BMI surveillance. Many states recently conducted their first child BMI surveillance, suggesting that gaps in state data may be filled as states respond to the childhood obesity epidemic. Given recent evidence that the steep upward trend in childhood obesity rates in the United States may be leveling, at least among certain sociodemographic groups $(19,30)$, public and political support for action may dwindle even though obesity rates are high and continue to increase among some groups. Particularly concerning is that national statistics, which suggest that childhood obesity rates may be leveling, may divert attention from disparities in child BMI according to socioeconomic status or race/ethnicity. State and local surveillance is better than national surveillance at capturing data on prevalence in local communities to identify those disproportionately affected.

Increasing investment in state and local child BMI surveillance is crucial to maintaining attention on the burden of childhood obesity in local communities. Locally representative child BMI data are also needed to evaluate the impact of policy and program efforts to reverse the epidemic. The public health community must make surveillance a priority to guide the investment of scarce intervention resources. Without a substantial increase in surveillance, policymakers have insufficient data to identify the most effective and cost-effective responses to the childhood obesity epidemic.

\section{Acknowledgments}

This work was supported by a grant from The JPB Foundation. It is solely the responsibility of the authors and does not represent the views of the funder. The authors reported no financial conflicts of interest.

\section{Author Information}

Corresponding Author: Kelly Blondin, MS, Nutrition Policy Institute, University of California, Division of Agriculture and Natural Resources, 2115 Milvia St, Ste 4, Berkeley, CA 94704. Telephone: 510-642-0295. Email: kblondin@ucanr.edu.

\footnotetext{
The opinions expressed by authors contributing to this journal do not necessarily reflect the opinions of the U.S. Department of Health and Human Services, the Public Health Service, the Centers for Disease Control and Prevention, or the authors' affiliated institutions.
} 
Author Affiliations: Catherine M. Giles, Angie L. Cradock, Steven L. Gortmaker, Harvard Prevention Research Center, Harvard Chan School of Public Health, Boston, Massachusetts; Michael W. Long, Department of Prevention and Community Health, Milken Institute School of Public Health, The George Washington University, Washington, DC.

\section{References}

1. Ogden CL, Carroll MD, Kit BK, Flegal KM. Prevalence of childhood and adult obesity in the United States, 2011-2012. JAMA 2014;311(8):806-14.

2. Fryar CD, Carroll MD, Ogden CL. Prevalence of obesity among children and adolescents: United States, trends 1963-1965 through 2009-2010. Hyattsville (MD): National Center for Health Statistics; 2012. https:/www.cdc.gov/nchs/ data/hestat/obesity_child_09_10/obesity_child_09_10.pdf. Accessed June 16, 2016.

3. Skinner AC, Skelton JA. Prevalence and trends in obesity and severe obesity among children in the United States, 1999-2012. JAMA Pediatr 2014;168(6):561-6.

4. Centers for Disease Control and Prevention. National Health and Nutrition Examination Survey. 2015. http://www.cdc.gov/ nchs/nhanes.htm. Accessed July 15, 2015.

5. Centers for Disease Control and Prevention, Division of Nutrition, Physical Activity and Obesity. Letter re PedNSS and PNSS. 2011. http://www.nj.gov/health/fhs/shapingnj/news/ newsletter/documents/Letter $\% 20$ re $\% 20$ PedNS S $\% 20$ and\%20PNSS.pdf. Accessed September 15, 2014.

6. Child and Adolescent Health Measurement Initiative. National Survey of Children's Health. http://childhealthdata.org/learn/ NSCH/nsch-more-info. 2015. Accessed July 15, 2015.

7. Centers for Disease Control and Prevention, Division of Adolescent and School Health. Youth Risk Behavior Surveillance System (YRBSS). 2015. http://www.cdc.gov/ healthyyouth/data/yrbs/index.htm. Accessed July 15, 2015.

8. Gosse MA. How accurate is self-reported BMI? Nutr Bull 2014;39(1):105-14.

9. Brener ND, Mcmanus T, Galuska DA, Lowry R, Wechsler H. Reliability and validity of self-reported height and weight among high school students. J Adolesc Health 2003; 32(4):281-7.

10. Longjohn M, Sheon AR, Card-Higginson P, Nader PR, Mason M. Learning from state surveillance of childhood obesity. Health Aff (Millwood) 2010;29(3):463-72.

11. Oza-Frank R, Siegal MD. Body mass index measurement in schools: partnering with oral health. J Public Health Dent 2011;71(4):301-7.
12. Nihiser AJ, Lee SM, Wechsler H, McKenna M, Odom E, Reinold C, et al. BMI measurement in schools. Pediatrics 2009;124(Suppl 1):S89-97.

13. Ruggieri DG, Bass SB. A comprehensive review of schoolbased body mass index screening programs and their implications for school health: do the controversies accurately reflect the research? J Sch Health 2015;85(1):61-72.

14. Linchey J, Madsen KA. State requirements and recommendations for school-based screenings for body mass index or body composition, 2010. Prev Chronic Dis 2011; 8(5):A101.

15. Sandoval A, Turner L, Nicholson L, Chriqui J, Tortorelli M, Chaloupka FJ. The relationship among state laws, district policies, and elementary school-based measurement of children's body mass index. J Sch Health 2012;82(5):239-45.

16. Flaherty MR. "Fat letters" in public schools: public health versus pride. Pediatrics 2013;132(3):403-5.

17. Porta M, editor. Dictionary of epidemiology. 5th edition. New York (NY): Oxford University Press; 2008.

18. Li W, Buszkiewicz JH, Leibowitz RB, Gapinski MA, Nasuti LJ, Land TG. Declining trends and widening disparities in overweight and obesity prevalence among Massachusetts Public School Districts, 2009-2014. Am J Public Health 2015; 105(10):e76-82.

19. Drewnowski A, Rehm C, Kao C, Goldstein H. Poverty and childhood overweight in California Assembly districts. Health Place 2009;15(2):631-5.

20. Madsen KA, Weedn AE, Crawford PB. Disparities in peaks, plateaus, and declines in prevalence of high BMI among adolescents. Pediatrics 2010;126(3):434-42.

21. Alviola PA 4th, Nayga RM Jr, Thomsen MR, Danforth D, Smartt J. The effect of fast-food restaurants on childhood obesity: a school level analysis. Econ Hum Biol 2014; 12:110-9.

22. Sage WM, Balthazar M, Kelder S, Millea S, Pont S, Rao M. Mapping data shape community responses to childhood obesity. Health Aff (Millwood) 2010;29(3):498-502.

23. O'Connor DP, Lee RE, Mehta P, Thompson D, Bhargava A, Carlson $\mathrm{C}$, et al. Childhood Obesity Research Demonstration project: cross-site evaluation methods. Child Obes 2015; 11(1):92-103.

24. Nihiser AJ, Lee SM, Wechsler H, McKenna M, Odom E, Reinold C, et al. BMI measurement in schools. Pediatrics 2009;124(Suppl 1):S89-97.

25. Crawford PB, Hinson J, Madsen KA, Neumark-Sztainer D, Nihiser AJ. An update on the use and value of school BMI screening, surveillance, and reporting. Child Obes 2011; 7(6):441-9.

The opinions expressed by authors contributing to this journal do not necessarily reflect the opinions of the U.S. Department of Health and Human Services, the Public Health Service, the Centers for Disease Control and Prevention, or the authors' affiliated institutions. 
26. Taveras EM, Marshall R, Horan CM, Gillman MW, Hacker K, Kleinman KP, et al. Improving children's obesity-related health care quality: process outcomes of a cluster-randomized controlled trial. Obesity (Silver Spring) 2014;22(1):27-31.

27. Lehmann CU, O’Connor KG, Shorte VA, Johnson TD. Use of electronic health record systems by office-based pediatricians. Pediatrics 2015;135(1):e7-15.

28. Leu MG, O’Connor KG, Marshall R, Price DT, Klein JD. Pediatricians' use of health information technology: a national survey. Pediatrics 2012;130(6):e1441-6.

29. Stanford FC, Taveras EM. The Massachusetts school-based body mass index experiment: gleaning implementation lessons for future childhood obesity reduction efforts. Obesity (Silver Spring) 2014;22(4):973-5.

30. Ogden CL, Carroll MD, Fryar CD, Flegal KM. Prevalence of obesity among adults and youth: United States, 2011-2014.

NCHS Data Brief 2015;219(219):1-8.

The opinions expressed by authors contributing to this journal do not necessarily reflect the opinions of the U.S. Department of Health and Human Services, the Public Health Service, the Centers for Disease Control and Prevention, or the authors' affiliated institutions. 


\section{Tables}

Table 1. Surveillance Practices of the 14 States That Have Surveillance Systems for Collecting Data on Child Body Mass Index (BMI), United States, 2014-2015

\begin{tabular}{|c|c|c|c|c|c|c|c|c|c|}
\hline State & Method $^{\text {b }}$ & $\begin{array}{c}\text { Sample } \\
\text { type }^{c}\end{array}$ & $\begin{array}{l}\text { Policy } \\
\text { Mandate }^{d}\end{array}$ & $\begin{array}{l}\text { Grades } \\
\text { Surveyed }\end{array}$ & $\begin{array}{l}\text { No. of Years } \\
\text { Data } \\
\text { Collected }\end{array}$ & $\begin{array}{l}\text { Survey } \\
\text { Interval }\end{array}$ & $\begin{array}{l}\text { Longitudinal } \\
\text { Data }^{e}\end{array}$ & $\begin{array}{l}\text { Locał } \\
\text { Data }\end{array}$ & Sample Size \\
\hline Arkansas & $\begin{array}{l}\text { School health } \\
\text { screen }\end{array}$ & Census & Yes & Even K-10 & 11 & Annual & Yes & Yes & 178,631 \\
\hline California & $\begin{array}{c}\text { School fitness } \\
\text { test }\end{array}$ & Census & No & $5,7,9$ & 17 & Annual & Yes & Yes & $1,335,931$ \\
\hline Florida & $\begin{array}{l}\text { School health } \\
\text { screen }\end{array}$ & Census & Yes & $1,3,6$ & 7 & Annual & No & Yes & 484,694 \\
\hline Georgia & $\begin{array}{c}\text { School fitness } \\
\text { test }\end{array}$ & Census & Yes & $1-12$ & 3 & Annual & Yes & Yes & $1,139,998$ \\
\hline Maine & School survey & Sample & Yes & $K, 3,5$ & 3 & Biennial & No & Yes & 11,484 \\
\hline Massachusetts & School survey & Census & Yes & $1,4,7,10$ & 3 & Annual & No & Yes & 205,975 \\
\hline Mississippi & School survey & Sample & No & $\mathrm{K}-12$ & 5 & Biennial & No & No & 480,321 \\
\hline New Mexico & School survey & Sample & No & $K, 5$ & 3 & Annual & Yes & No & 3,949 \\
\hline Pennsylvania & $\begin{array}{l}\text { School health } \\
\text { screen }\end{array}$ & Census & Yes & $\mathrm{K}-12$ & 7 & Annual & Yes & Yes & $1,803,689$ \\
\hline Tennessee & $\begin{array}{l}\text { School health } \\
\text { screen }\end{array}$ & Census & No & $\begin{array}{l}\text { Even K-8, } \\
\text { one high } \\
\text { school year }\end{array}$ & 7 & Annual & No & Yes & 276,877 \\
\hline Texas & $\begin{array}{c}\text { School fitness } \\
\text { test }\end{array}$ & Census & Yes & $\begin{array}{l}\text { 3-8, one high } \\
\text { school year }\end{array}$ & 8 & Annual & Yes & Yes & $2,903,200$ \\
\hline Utah & School survey & Sample & No & $1,3,5$ & 5 & Biennial & No & No & 4,477 \\
\hline West Virginia & $\begin{array}{l}\text { School health } \\
\text { screen }\end{array}$ & Census & Yes & 2 & 10 & Annual & No & Yes & 8,591 \\
\hline Wisconsin & Population survey & Sample & No & Not reported & 1 & Annual & No & $\begin{array}{l}\text { Not } \\
\text { reported }\end{array}$ & Not reported \\
\hline
\end{tabular}

${ }^{a}$ These states have child BMI measurement programs that satisfy the criteria for a surveillance system: 1) height and weight are measured and reported by a trained professional; 2) data are state-representative for the age groups included in the survey or census sample; 3 ) data are collected at least every 2 years with plans to continue; and 4) data are aggregated, analyzed, and reported at the state level.

${ }^{\mathrm{b}}$ A school-based survey entails measuring child health indicators at school for surveillance purposes only; a school health screen involves measuring health indicators to inform parents/guardians of their child's health status; a school fitness test is designed to assess selected measures to produce a composite score of overall physical fitness; and a population survey collects data on a randomly selected representative sample drawn from the population of interest.

${ }^{\mathrm{C}} \mathrm{A}$ census sample includes all children in a population of interest; a sample is a randomly selected subgroup of children selected or retrospectively weighted to represent a population of interest.

${ }^{\mathrm{d}}$ Policy mandate for fitness testing or BMI screening but not BMI surveillance.

e Longitudinal data refers to BMI data collected on the same children over time; each child's data are linked by a unique identifier.

${ }^{f}$ Local-level data were reported by 9 of the 14 states; 5 reported school-level data, 6 reported school district-level data, and 5 reported county-level or public health district-level data.

${ }^{g}$ Sample or census size based on most recently published data.

The opinions expressed by authors contributing to this journal do not necessarily reflect the opinions of the U.S. Department of Health and Human Services, the Public Health Service, the Centers for Disease Control and Prevention, or the authors' affiliated institutions. 
Table 2. US States ${ }^{a}(n=21)$ That Collect Data on Child Body Mass and Meet at Least One Criterion for a Surveillance System but Do Not Have a Surveillance System, 2014-2015

\begin{tabular}{|c|c|c|c|c|c|}
\hline \multirow[b]{2}{*}{ State } & \multirow[b]{2}{*}{ Method } & \multicolumn{4}{|c|}{ Surveillance Criteria Met $^{\text {b }}$} \\
\hline & & $\begin{array}{c}\text { Height and Weight } \\
\text { Measured by a Trained } \\
\text { Professional }\end{array}$ & $\begin{array}{l}\text { Data Are Collected at } \\
\text { Least Every } 2 \text { Years }\end{array}$ & $\begin{array}{l}\text { Data Are State } \\
\text { Representative }\end{array}$ & $\begin{array}{l}\text { Data Are Aggregated, } \\
\text { Analyzed, and } \\
\text { Reported }\end{array}$ \\
\hline Alabama & $\begin{array}{l}\text { School-based oral health } \\
\text { screen/survey }\end{array}$ & $x$ & & $x$ & $x$ \\
\hline Alaska & $\begin{array}{l}\text { School-based oral health } \\
\text { screen/survey }\end{array}$ & $x$ & $x$ & & $x$ \\
\hline Arizona & $\begin{array}{l}\text { School-based oral health } \\
\text { screen/survey }\end{array}$ & $x$ & & $x$ & $x$ \\
\hline Colorado & $\begin{array}{l}\text { School-based oral health } \\
\text { screen/survey }\end{array}$ & $x$ & & $x$ & $x$ \\
\hline Hawaii & School entry physical & $x$ & $x$ & $x$ & \\
\hline Idaho & School-based survey & $x$ & & $x$ & $x$ \\
\hline Illinois & $\begin{array}{l}\text { School-based oral health } \\
\text { screen/survey }\end{array}$ & $x$ & & $x$ & $x$ \\
\hline Kentucky & School entry physical & $x$ & $x$ & & $x$ \\
\hline Louisiana & School-based fitness test & $x$ & $x$ & & $x$ \\
\hline Minnesota & School entry physical & $x$ & $x$ & $x$ & \\
\hline Nebraska & School health screen & $x$ & $x$ & $x$ & \\
\hline New Hampshire & $\begin{array}{l}\text { School-based oral health } \\
\text { screen/survey }\end{array}$ & $x$ & & $x$ & $x$ \\
\hline New Jersey & School-based screen & $x$ & $x$ & $x$ & \\
\hline New York & School-based survey & $x$ & $x$ & & $x$ \\
\hline North Carolina & School entry physical & $x$ & $x$ & $x$ & \\
\hline North Dakota & $\begin{array}{l}\text { School-based oral health } \\
\text { screen/survey }\end{array}$ & $x$ & & $x$ & $x$ \\
\hline Ohio & $\begin{array}{l}\text { School-based oral health } \\
\text { screen/survey }\end{array}$ & $x$ & & $x$ & $x$ \\
\hline Oklahoma & School-based fitness test & $x$ & $x$ & & $x$ \\
\hline South Dakota & School-based survey & $x$ & $x$ & & $x$ \\
\hline Virginia & School entry physical & $x$ & $x$ & $x$ & \\
\hline Washington, DC & School entry physical & $x$ & $x$ & & $x$ \\
\hline
\end{tabular}

${ }^{a}$ Among 50 states and Washington, DC $(n=51)$.

${ }^{\mathrm{b}}$ Criteria for a surveillance system: 1) height and weight are measured and reported by a trained professional; 2) data are state-representative for the age groups included in the survey or census sample; 3 ) data are collected at least every 2 years with plans to continue; and 4) data are aggregated, analyzed, and reported at the state level.

The opinions expressed by authors contributing to this journal do not necessarily reflect the opinions of the U.S. Department of Health and Human Services, the Public Health Service, the Centers for Disease Control and Prevention, or the authors' affiliated institutions. 